\title{
The Relevance of the Vygotsky's Sociocultural Approaches to Promote Interaction in EFL Classroom
}

\author{
Theophile Muhayimana \\ Faculty of Education, University of Kibungo, Rwanda \\ E-mail:mzeekabambe@gmail.com
}

\begin{abstract}
This paper that is a theoretical inquiry by design aimed at analyzing the importance and implications of the Vygotskian sociocultural approaches (VSA) on teaching and learning English as a foreign language (EFL). Scholarship indicated that EFL learners' problems are tightly linked to the class culture that oftentimes involves teacher-centered instruction, rote learning, and restricted learner's involvement and self-motivation in the learning process. It is the premise of this paper that revisiting the class culture and use the VSA will contribute a great deal to addressing some of communication and classroom interaction issues in EFL context. First, at the onset, the paper discussed the relevance of the framework to the teaching and learning of EFL. Second, the study delved into the literature that reviewed the four fundamental components of the framework that are tightly related to promoting language learning and classroom interaction. These concepts include social environment and use of tools vis-à-vis the learning and development process, scaffolding, and the notion of the zone of proximal development. Third, the paper looked into the implications of the VSA on enhancing interaction in EFL classroom that focused on knowledge about learners to better assist them, promotion of classroom discourse, and collaborative learning environment. Fourth, the conclusion underscored the paramount importance of the collaborative learning
\end{abstract}


environment to sustain classroom interaction; that ending section also shed light on the limitations of the VSA and strategies to alleviate them.

Keywords: Vygotskian sociocultural approaches (VSA), interaction, EFL classroom

\section{INTRODUCTION}

Classroom interaction has always been at the heart of language teaching. Indeed, language learning takes place in an environment conducive to student engagement, synergy, and communication among students themselves and between students and teachers. There is no language classroom without interaction because "from the very beginning of language study, classrooms should be interactive" (Brown, 2007, p. 213). For the last three decades, practitioners and researchers have been concerned with ways and means to create and sustain classroom interaction both the teacher-learner and student-student interaction (Eun \& Lim, 2009; Xia, 2014). Indeed, in the classroom setting, effective learning occurs through dynamic interaction that includes a couple of factors such as information exchange and idea sharing, assistance, and collaboration, meaning negotiation, as well as asking and answering questions.

Consequently, interaction is considered one of the core components of classroom practices that create, boost, and sustain an environment that is conducive to successful language learning. Good environment in language learning, including interaction, dialogue, and meaning negotiation, constitutes the essence of learning itself (Kumaravadivelu, 2003; Samana, 2013).

There is abundant literature on multiple and diverse methods that aimed at enhancing classroom interaction and language learning drawing on theories of human development (Eun \& Lim, 2009; Richards \& Rodgers, 2001; Xia, 2014). Behaviourists preached the language teaching methods like audio-lingual methods and grammar-translation with emphasis on memorization and language drills (Asl, 2015; Mart, 2013). Cognitivists including Piaget, Chomsky, and Krashen seemed to find the roots of knowledge acquisition solely in biological functions. Cognitivists contended that the child attains cognitive maturation and learns thanks to his mental functions alone. From a cognitivist perspective, knowledge construction and understanding - including learning - is rather endogenetic than exogenetic. It takes place, not from the external input, but within the child's mind, at his intrapersonal plane that allows the child to understand, organize and respond to various situations (Piaget, 1971). Cognitivist approaches to language learning led to language teaching methods such as the natural approach that underscores the learner's inborn abilities and biological predispositions in language acquisition (Piaget, 1971; Richards \& Rodgers, 2001).

Finally, still in the search for enhancing the learning environment and promoting interactive principles, the sociocultural theories developed by Vygotsky 
posited that human development is a result of a system of social connections and relations. Any learning activity draws on the social, cultural, and historical environment (Shaban, 2016; Turk, 2008). Negotiation and creation of meanings in language acquisition is never an individual endeavor, rather it is a collaborative act where a child learns from an adult or a more knowledgeable peer through assistance, interaction, and use of multiple tools including language (Wertsch, 1985; Vygotsky, 1978; Vygotsky, 1999).

Research outlets in educational psychology have indicated the importance and contribution of the Vygotskian framework to successful teaching and learning in general and in some fields such as sciences and teacher education (Belland, 2017; Haider \&Yasmin, 2015; Harland, 2003;Kozulin, 2003; Lindblom, \& Ziemke, 2002; Lourenço, 2012; Mahn, 2012; Shaban, 2016b). English language teaching professionals have also explored the contribution of the sociocultural approaches to teaching English as a second or a foreign language from various perspectives in different settings (Lee, 2015; Poehner \& Infante, 2016; Rezaee \& Azizi, 2012; Samana, 2013; Shaban, 2016a; Turk, 2008).

However, no study has explicitly looked into the potential of Vygotsky's legacy in educational psychology in promoting and sustaining classroom interaction in EFL context. Yet, in such settings, teaching English for communicative purposes still faces hard-to-remove stumbling blocks including instructional pedagogies, lack or insufficiency of teaching/learning materials, social, economic, and political constraints both on student and teacher side. This study thus intended to rethink the EFL classroom culture by using the sociocultural framework to create and sustain learning-centered practices, student engagement, and synergy that are conducive to improving, creating, and sustaining an interactive and communicative environment in EFL classrooms. Nevertheless, before delving into the heart of the study, we consider exploring the snapshots of the core concepts of the Vygotskian sociocultural approaches in the next section.

\section{OVERVIEW OF THE VSA FUNDAMENTALS}

Lev Semyonovich Vygotsky (1896-1934) is a Russian psychologist whose many interests included the domains of child development, developmental psychology, and education. Vygotsky was instructed through an extended critical inquiry and philosophical discussions, known as Socratic dialogue (Haider \&Yasmin, 2015). This type of education greatly influenced Vygotsky's views on the relevance and role of social dialogue and interaction as well as the cultural environment in the learning and development process (Rule, 2015; Sullivan, Smith, \& Matusov, 2009; Verenikina, 2010).

According to the sociocultural framework, any learning and mental activity is viewed as an interaction and interconnection between social agents and physical environment. The theory thus has a significant emphasis on the role of action in social, historical, and cultural context (Ibrahim, 2012; Samana, 2013). Among the many concepts found and investigated in the sociocultural framework and those most closely to this study looking into English language learning and classroom 
interaction are the social environment and use of tools, scaffolding, and the notion of the zone of proximal development.

\subsection{Social Environment and the Learning Process}

From Vygotsky's perspective, social interaction and cultural environment are key factors to the learning process and human being's cognitive development. At the very beginning, a neonatal life and survival depend on the social environment, mainly adult people around the baby providing it with the first basic care such as feeding, bathing, clothing and such. In this line, Vygotsky (1998) stated that

"The most elementary and basic vital needs of the infant can be satisfied in no other way than with the help of adults. The path through others, through adults, is the basic path of the child's activity at this age. Definitely, everything in the behavior of the infant is intertwined and interwoven into the sociable. Such is the objective situation of his development". (p. 215)

The above statement implies that, without adults' care, a baby's life would be at high risk. Additionally, not only does a child significantly depend on the adults around him to meet his first physiological necessity, he also needs, follows, and imitates their actions to acquire some aspects of the social life. Through intercommunication with the surroundings, the child, step by step, picks some social behaviors. From the preliminary perceptions like sight, hearing and grasping, the child gradually acquires language and other mental abilities such as thinking, memory, decision-making, etc. His personality is imbued with all facets of the social life around him. In this vein, Vygotsky (1998) admitted that

"at the beginning of each age period, there develops a completely original, exclusive, single, and unique relation, specific to the given age, between the child and reality, mainly the social reality, that surrounds him. We call this relation the social situation of development at the given age. The social situation of development represents the initial moment for all dynamic changes that occur in development during the given period. It determines wholly and completely the forms and the path along that the child will acquire ever newer personality characteristics, drawing them from the social reality as from the basic source of development, the path along which the social becomes the individual." (p. 198)

The social environment molds and nurtures individual development and personality at every single phase of one's life. Actually, children who were isolated from the social atmosphere developed unusual ways of life. History abounds in cases of children who demonstrated savage comportment with scarce human behavior, just because they grew up in a wild environment without any social contact. Genie or the feral child in California (Friedmann \& Rusou, 2015; Sang, 2017), Oxana Malaya in Ukraine (Regan, 2016), and Victor of Aveyron in France (Nawrot, 2014) are few examples among so many. Overall, the learning process and children's mental functions such as memory, language, and attention tend to develop following the social and cultural norms and practices of his environment. 


\subsection{Semiotic Mediation}

The social interaction that carries and facilitates the learning process does not happen in a vacuum, it is mediated by tools. In this context, tools should be understood, in general terms, as an instrument used as a means of accomplishing a task or purpose. Vygotsky (1978) talked about two kinds of tools. The first category includes material tools that do not have any special symbolic representation. They are merely physical by nature without being worked or assigned a special function or meaning by human beings. Such tools are like a piece of wood, a stone, a rope, etc. The second type is called psychological tools or signs. They are human inventions with a symbolic representation and more elaborate. They bear a culture-embedded meaning, such as counting system, algebraic symbols, artifacts, maps, and language (Kozulin 2003; Turuk, 2008; Wertsch 1985).

Vygotsky highly valued psychological tools because human beings created them to fulfill specific social functions. Among the psychological tools, Vygotsky elaborated on language that he considered as the tool par excellence. Functionally speaking, language is first viewed as a bridge between social environment and an individual child; it connects the external world to the child's internal plane, as Vygotsky (1978) explained

"Prior to mastering his own behavior, the child begins to master his surroundings with the help of speech. This produces new relations with the environment in addition to the new organization of behavior itself. The creation of these uniquely human forms of behavior later produce the intellect and become the basis of productive work: the specifically human form of the use of tools." (p. 25)

The adults interact with the child, cherish and cradle him, instruct and guide him more often than not through language. Likewise, children seek and capture information, receive and react to the feedback through language as well (Behroozizad, Nambiar, \& Amir, 2014). In the first place, language, better than any other sign, mediates communication between the child and the adults at home, in a community gathering, or at school. Either written or oral, language is the major vehicle of knowledge in various domains that a generation passes on to another (Lindblom \& Ziemke, 2002; Verg \& Kotz, 2013).

Beyond social interaction and knowledge transmission, language helps the child organize his thinking. Through speech, a child learns to verbally express his ideas, desires, and intentions. More importantly, language is an indispensable adjuvant for a child to accomplish any act as it helps him define, plan, and perform his actions. Indeed, in his experiment about language acquisition and use, Vygotsky (1978) noticed that

"A child speech is as important as the role of action in attaining the goal. Children not only speak about what they are doing; their speech and action are part of one and the same complex psychological function, directed toward the solution of the problem at hand." (p. 26) 
The description of the role of language in the above paragraphs suggests that the importance of language in the learning process cannot be overstated in social life in general, and in school settings in particular (Lee \& Bucholtz, 2015). At the intrapersonal level, language helps the learner organize his ideas, understand the class materials and handle any classroom task. At the interpersonal level, learners use language to interact with peers, teachers, and staff (Lourenço, 2012; Shaban, Khatib, \& Ebadi, 2010). Thus, language seems to be the preeminent tool for learners to survive in the school settings.

\subsection{Scaffolding}

Scaffolding is a metaphorical term coined by Wood, Bruner, and Ross (1976) to mean the assistance that an adult, a more experienced person provide to a novice or a child and enable them, step by step, to accomplish a task that the child could not complete on his own. Through scaffolding, a child can carry out a task, solve a problem, or attain a goal that they could not achieve if left unassisted. "The adult let the child play with a task which was above the child's current ability but within his/her capacity for a while and only intervened when he/she got into difficulty and needed assistance (Khaliliaqdam, 2014, p. 892).

Simply put, scaffolding, in the academic context, is about learning through assistance provided by an adult or collaboration with more capable peers. Ellis (2003) defined scaffolding as "the dialogic process by which one speaker assists another in performing a function that he or she cannot perform alone" (p. 180).In other words, using tools such as language or other visual or audiovisual materials, the teacher or any other elder can provide encouragement, comments, guidelines, and instructions that may help the child go through a task that he may not perform without a help (Belland, 2017; Mahn, 2012).

A child may start working on an activity and gets stuck on his way. However, when an adult steps in and provides some clarifications, demonstration, examples, re-statement of the question or task, the learner can find some more light and facility to handle his task successfully, what he would not have achieved if he had been left alone (Eun \& Lim, 2009; Lee, 2015). Likewise, collaboration with companions can boost the children's learning process. Indeed, when learners come together and join efforts to work on a task, they are likely to face fewer challenges than when each child works individually (Behroozizad, Nambiar, \& Amir, 2014; Samana, 2013).

As the saying goes "many hands make the work lighter". In this regard, study groups or group discussions seem to be invaluable venues where learners can meet and help one another for a clearer understanding of materials covered in class.

Such groups or any other kind of encounters may be useful places where learners meet for regular interaction, share experience, and seek information from one another. In such cooperative environment, weaker learners find convenient space and time to ask for clarification and help from their more knowledgeable peers (Ibrahim, 2012; Lange, Costley, \& Han, 2016). 


\subsection{Zone of Proximal Development}

In addition to social interaction and tool use, a child understands his environment, masters his perceptions, and learns thanks to the support from adults, as well as collaboration with more experienced peers. With assistance from a senior, a child can carry out and achieve a task that he would not accomplish on his own (Lin, 2016). This is what Vygotsky (1978) called the zone of proximal development (ZPD), which he defined as "the distance between the actual developmental level as determined through independent problem solving and the level of potential development as determined through problem solving under adult guidance or in collaboration with more capable peers" (p. 86). In other words, the ZPD is the gap between the current or actual level of development of a learner and the next level that can be reached through collaboration and assistance (Behroozizad, Nambiar \& Amir, 2014; Shaban, Khatib, \& Ebadi, 2010).

The ZPD can also be understood as the learner's potential ability, cognitively prepared, in the process of maturing, that needs help and social interaction to fully develop (Turuk, 2008). The idea is that individuals learn best when working together, and more knowledgeable ones helping novices to understand concepts and notions or perform tasks that they could not achieve on their own without assisted efforts, support, and collaboration (Mahn, 2012; Shaban, Khatib, \& Ebadi, 2010).

\section{IMPORTANCE OF THE VYGOTSKYIAN APPROACH IN EFL CONTEXT}

English as a foreign language (EFL) corresponds to the expanding circles according to Kachruvian model that describes the English language functions and roles around the world (Klimezak-Pawl, 2014). EFL is a traditional term to refer to the use or study of the English language by non-native speakers in countries where English is not used as a local channel of communication (Nordquist, 2017). In the EFL context, the use of English has not a significantly vital role in everyday life and communication. In some countries, English does not have an official status; it is taught in schools as a subject matter and used in classroom settings only. EFL is generally taught and learned in environments where the language of the community and the school is not English (Nordquist, 2017).

Consequently, given the nature of the EFL context where English teaching and learning are oftentimes confined in classroom four walls, instructional and pedagogic practices are challenging to both teachers and students. Teachers have difficulties finding access to and providing English models for their students (Tsang, 2017). In actual facts, in addition to some issues that prevail in EFL settings such as lack of sufficient and relevant teaching materials, larger class size, teachers still use traditional teaching methods. The textbook that more often than not does not match the local context is the only teaching aid. In teacher-fronted style, the teacher who is viewed as the only knowledge producer instructs the whole class whereby students have very restricted room to interact communicatively, talk about and share their lived learning experiences.

Such pedagogical instruction and learning environment do not give learners opportunities to interact communicatively. The teacher takes too much to talk, and 
learners listen passively, and some get bored end up taking a nap (Mark, 2010). As Behroozizad, Nambiar, and Amir (2014) indicated, in such a teaching environment, students become very passive and dependent on the teacher.

In addition to predominantly teacher-centered teaching methods, most teachers and students only use the English language in the classroom and both communicate in local languages outside the classrooms, at home, and in business. Then learners are engaged in passive learning and instructed mostly about grammar rules for English; and lose interest in English, feeling it is just too hard for them. Even though learners have a good understanding of English grammar, it does not help them much. In most cases, teaching EFL tends to be dominated by focusing on massive memorization of vocabulary and grammar rules. It is also felt that learners do not use English outside the classroom, because the lessons given to them in class focus on tedious grammatical rules with very little time to practice English in real-life situations; such as during daily conversations among the learners or in form of planned exciting activities at schools.

In the same vein, Razak, Saeed, and Ahmad (2013) also indicated challenges that both students and teachers face in EFL countries when it comes to promote and sustain classroom interaction, a key factor to student engagement. They stated

"the majority of English as a foreign language (EFL) classrooms tend to lack the necessary characteristics of interactive learning environment where learners can be engaged in active participation and dynamic interaction to use and practice English for various authentic purposes [...]. This learning environment restricts EFL teaching and learning to deliver and receive information with no or fewer opportunities for their students to interact and collaborate actively in classroom activities [...].” (p. 187)

From the above statements, it can be deducted that EFL learners' problems are tightly linked to the class culture that involves teacher-centered instruction, rote learning, and restricted learner's involvement and self-motivation in the learning process. This paper postulates that rethinking the class culture and using the VSA are more likely to mitigate some of communication and classroom interaction issues faced in EFL context. Language learning depends greatly on the classroom's social life. Therefore, the VSA underscore that consideration of social and cultural process and interactions, as well as the use of signs and tools as vehicles for constructing knowledge are an effective alternative pedagogic route to improve, create, and sustain an interactive and communicative environment in EFL classrooms.

Therefore, addressing traditional pedagogical practices that impede student engagement and self-assessment, the VSA offer multiple and varied types of tool such as diaries, posters, as well as a wide range of activities and information sharing tasks such as jigsaw, information gap and problem solving tasks, decision making, role-play, etc. (Abate, 2014). From the VSA perspective, collaboration rather than competition and individual work create a favorable learning environment where novices get assistance from more experienced classmates. The teacher no longer instructs, but he is a facilitator who steps in order to gauge student ability to solve a task, guide, and assist. As they work on these tasks and activities, students are given 
golden opportunities to understand and learn from one another. Such collaborative environment between teacher and students and among students themselves is likely to promote classroom interaction and student engagement and learning. In the same line of thought, Behroozizad, Nambiar, and Amir (2014) pointed out the role and importance of collaboration and classroom interaction in the learning process. They said, "this enhanced interactive relationship is supposed to raise students' interest and motivation in exploring natural features of the target language, which could result in effective communication by employing a set of learning strategies" ( $p$. 223).

\section{THE IMPLICATIONS OF THE VSA ON ENHANCING INTERACTION IN EFL CLASSROOM}

As discussed in previous sections, education practitioners have investigated the sociocultural framework for its potential to enhance teaching and learning practices from various perspectives (Lee, 2015; Poehner \& Infante, 2016; Razak, Saeed, \& Ahmad, 2013; Samana, 2013; Shaban, 2016a; Turk, 2008. Beyond classroom practices, the approach has been even used as a tool in teacher professional development (Shaban, 2016b; Shaban, Khatib, \& Ebadi, 2010). The study at hand analyzed the contribution of the framework to promote and sustain classroom interaction in EFL settings. More specifically, the study examined first the role of the ZPD to help teachers get to know learners to better help them in studying endeavors. Second, the possibilities of semiotic mediation to improve classroom dynamic and synergy with focus on effective classroom talk are scrutinized because classroom discourse is the major channel for any learning and teaching activity. Third, instead of and beyond mere assistance, the VSA proposes scaffolding as one of the multiple and powerful strategies to boost collaborative learning opportunities in EFL classrooms.

\subsection{ZPD at Work: Knowledge about Learners to better Assist Them}

Undoubtedly, one of most Vygotsky's powerful legacy and contributions to educational psychology is the ZPD concept. This notion refers to the account and importance of both the actual or current level of development on the one hand and learners' potential ability to acquire new knowledge and carry out activities when assisted or working with peers, on the other hand. The application of the ZPD concept to EFL classroom settings implies that at onset of any instructional activities, language teachers need to know student differences or who their students are in terms of socioeconomic status, learning styles and challenges, and previous education background (Felder \& Brent, 2005; Rahman, Scaife, Yahya, \&Jalil, 2010).

Moreover, from a constructivist perspective, previous and existing knowledge is a great asset to solve problems and create new knowledge (Huang, 2002). This relationship between what a learner knows and can do informs teachers about what learners need to know. Ausubel (as cited in Harland, 2003) underscored the link between what the learner already knows and can do, and what is to be learned. $\mathrm{He}$ said

"Whatever strategy a teacher uses, each student will construct their own 
meaning based on an interaction between prior knowledge and current learning experiences. If I had to reduce all of educational psychology to just one principle, I would say this: the most important single factor influencing learning is what the learner already knows. Ascertain this and teach him accordingly" (p. 266).

As a matter of fact, in EFL context whereby learners are non-native English speakers and do not use English in daily communication may have learned the English language in different settings, for different periods of time, and for multiple purposes (Samana, 2013).Therefore, inquiry and information about learners help teachers make an informed decision about course content, learning outcomes and goals, as well as instructional strategies. In this regard, Gebhard (2005) indicated that reflective teachers are aware that the starting point to promote interaction factors is to be informed about learners' background, their needs, and learning strategies. He said that

[a] number of educators encourage language teachers to take on the role of needs assessor. Doing so includes learning about students' language-learning history, goals, interests, study habits, learning strategies, and languagelearning styles. They suggest we interview students, have them complete questionnaires, and generally observe what they do and say. (p. 57)

Xuesong (2006) too recommended that EFL teachers should give time to students and listen to their learning experience, as the initial step for the classroom interaction. "What teachers really need to do is commit a substantial amount of energy and time to listening to students' past and current learning stories and seeking mutual understanding about teachers' and students' roles" (p. 73).

Moreover, teachers would need to be aware of their students' attitudes with regard to social interaction beliefs and practices, which might positively or negatively affect their interaction in a classroom setting. In other words, EFL learners might seem apathetic not because they are ignorant but because social or psychological factors impede their self-disclosure (Gebhard, 2005). In such a case, committed teachers approach learners to know what is wrong with them. Therefore, this diagnosis allows teachers to make informed decisions to help learners take part in classroom activities (Roorda, Koomen, Spilt, \& Oort, 2011).

As was mentioned previously, interaction works in both directions: learnerteacher and leaner-learner. In some classes, some learners would seem lethargic and never raise hand or talk because they are dominated by the brightest ones who are always given the first chance to speak, or they proudly and confidently jump in and talk. Therefore, teachers are advised to be careful and make sure that shy or less talented students are not left behind. One of the strategies is to know and call each student by their name. In such a case, the learner will notice that s/he is a part of the class rather than a stranger or an anonymous individual ignored by the teacher. This strategy makes all students attentive and involved in classroom interaction. In such circumstances, Farrell (2007) suggested that:

(...) Teachers can call on students who do not raise their hands to see why they 
think they cannot answer the question. It may be that they know the answer but they may not want to answer in public. Teachers also have the option of calling a student's name first, and then asking the question. This alerts the student that a question is coming his/her way: 'Suzie, what do you think?' (p. 88)

From a sociocultural perspective, information about learner's previous knowledge, learning history and preferences, as well as goals and challenges are key to EFL teachers to design and deliver the right content to the right students. Indeed, knowing and considering each student in the classroom as an individual case help teachers avoid looking at the class just as a bunch of individuals. Rather, treating each student as a unique case enables teachers to act out of love, humility, and cooperation, which are core ingredients of dialogical and interactionist learning paradigm (Freire, 1970; Razak, Saeed, \& Ahmad, 2013). Such teacher behaviors are believed to promote teacher-learner partnership and collaboration, as well as meaning negotiation with students, which is likely to stimulate learners to "be engaged in active participation and dynamic interaction to use and practice English for various authentic purposes [...] This learning environment is conducive to EFL learning" (Razak, Saeed, \& Ahmad, 2013, p. 187.

\subsection{Promotion of Classroom Discourse}

Central to the sociocultural theory is the idea that human development and learning are mediated or facilitated by tools such as cultural practices, artifacts, various systems for counting, and mnemonic techniques (Gibbons, 2003; Shaban, 2016a; Wells, 1994). According to Vygotsyky (1978), language is a tool par excellence; it is a unique human invention that enables human beings to achieve the goal of social living. Lin (2016) underscored the paramount importance of language in the learning endeavor, and stated that "in order for learning to process from the social to the individual level, language serves as a psychological tool to regulate objects, others, and oneself in organizing functions that are critical to mental activity" (p. 12). In the same line of showing the tight interconnections between language and social activity, Wells (1994) pointed out that

"For language not only functions as a mediator of social activity, by enabling participants to plan, coordinate, and review their actions through external speech; in addition, as a medium in which those activities are symbolically represented, it also provides the tool that mediates the associated mental activities in the internal discourse of inner speech.” (p. 7)

In class settings, language is the chief medium of teaching and learning. Language or classroom talk is the major vehicle children use to actively engage in the learning process and teachers constructively facilitate the process (Andrew, Cobb, \& Giampietro, 2005; Zhang, 2008). Therefore, given that in classroom learning and teaching, a large proportion of time is spent in talking and listening, the quality of classroom talk between children and teachers and among learners themselves is of a paramount importance because it affects the classroom interaction 
and "sets a suitable climate for learning and transmitting teachers' expectations for their pupils' thinking" (Zhang, 2008, p. 80). In this regard, abundant literature indicated that much of classroom talk is heavily dominated by the triadic dialogue or a three-part questioning-answering sequence: teacher initiation, student response, and teacher evaluation or follow-up (IRE or IRF) (Chin, 2007; Farrell, 2007; Parsell, 2000).

The core concern now is to know if all questions contribute equally to student learning and classroom interaction. In this regard, Skidmore, Perez-Parent, \& Arnfielf (2003) argued that there are three types of questions: the close-ended category, the open-ended, and the multiple-answer questions. Wood (1992) argued that closed and Wh-type questions constrain students to give short responses that lead to less participation and misunderstanding. The open-ended type enables students to get more cognitively challenged and engaged in the learning process. The third category encompassing questions with an indeterminate number of possible answers "are authentic which the teacher does not know what the pupils will answer" (Skidmore, Perez-Parent, \& Arnfielf, 2003, p. 50). For class progress in general and learners' benefit in particular, Farrell (2007) encouraged teachers to use the first two categories of questions or referential ones rather than the first category or display-type ones. By so doing, teachers value learners' contribution and open discussions because they do not give a final answer. Farrell (2007) pointed out that:

$[w]$ hen teachers use exploratory-type speech, they are not giving the final word on an issue in that they are admitting that they do not know all answers. They do not use a type of language that emphasizes their authority as the expert on the topic at hand which is characteristic of final draft talk. (p. 81)

Therefore, thanks to referential questions, teachers value the voice of learners who feel comfortable and encouraged to drive in the flow of the classroom interaction. Furthermore, with regard to classroom interaction, floor sharing plays a great deal in language classroom when teachers dedicate enough time for learners to speak and express their ideas and share experience. Thus, Gebhard (2005) invited teachers not to monopolize the floor with lengthy and detailed explanations that end up boring learners and hindering interactions:

[i]f the teacher gives long explanations about language or long-winded speeches on abstract ideas, some students will sit back and shift into a passive temperament, accepting English as a subject in which the teacher lectures, sometimes in abstract terms that are beyond comprehension. (p. 70)

It cannot be overstated that classroom talk is the medium par excellence of any learning and teaching process. Upon that, the appropriate use of the classroom discourse should be meant to emulate students and stimulate learners exchange views, share experiences, and actively contribute to the language learning and knowledge construction at large. For this to happen and be sustained, EFL teachers are advised and encouraged to create a stress-free and friendly environment, initiate and facilitate the talking, and then step out to yield to students who need more room and time to make their voice heard, exchange their views, and share their lived 
experiences. Such effective use of classroom discourse leads to learner-learner and teacher-learner meaning negotiation and creation.

\subsection{Collaborative Learning Environment}

The notion of collaborative learning is deeply rooted in the sociocultural framework. According to Vygotsky (1978), individual development and the learning process are mediated by a social context as well as interaction and assistance from peers or adults. In other words, the learning process involves guidance, assistance, and mentoring provided by more knowledgeable persons, either by adults or peers, who engage in activity with less experienced persons in a process of guidance or collaboration (Lin, 2016). In the Vygotskian sociocultural framework, scaffolding is a dialogic and interactive exchange that "comprises efforts to reduce the complexity of tasks, recruit and maintain learner attention, assist learners through steps of task completion, and eventually hand over responsibility for the task to the learner (Poehner \& Infante, 2016, p. 4).

From this perspective, the development of an individual cannot be viewed only as the study of an individual. The external social world in which the individual life has developed should also be considered. Thus, learning, with regard to this notion, is "embedded within social events and occurring as a child interacts within people, objects and events in the environment" (Vygotsky, 1986, p. 287).

In EFL classroom, not only the teacher can assist students, even students with low level of English proficiency can also help their classmates. The teacher is not the only one to scaffold students. Novices or students with low English language proficiency can also help their peers. Ohta (2001) indicated that students can help their peers because each student has different strengths and weaknesses. Indeed, students take on different roles during classroom interaction. "While ones are speaking, the others are listening. Therefore, it is easy for them to notice problems their peers encountering and provide solutions" (Samana 2013, p. 343).

Through scaffolding, learners can interact with teachers and collaboratively learn, discuss and exchange with peers. Thus, scaffolding is intimately linked to the collaborative learning environment. According to the teaching and learning context, the collaborative language learning instruction was proven to be advantageous because it moderates the teachers' control and limits their speech for the learners' benefits. Consequently, as Kessler (1992) reported, collaborative learning offers learners more paces, which contributes to enhancing their interaction among themselves through collaboration in pair or group works:

[t]eachers in traditional classrooms do most of the talking. Cohen (1984) report that only 25-50 percent of the class may actually listen to the teacher. Less than $2 \%$ of traditional class time is devoted to student language production (Goodland, 1984), and low achievers are typically given fewer opportunities to participate (Cooper, 1979). (...). In contrast, up to $80 \%$ of cooperative learning class time may be scheduled for activities that include student talking. Because this student talk is simultaneous, half the students may be engaged in language comprehension. This results in increased active communication for all students. (p. 5) 
In the same line of thought, Kumaravadivelu (2003) underscored the importance of collaborative learning whereby teachers yield to learners, speak much less, and they intervene but to assist students in the performance of tasks only when asked to do so. He stated:

"In more practical terms, this means that teachers should seek to promote negotiated interaction by yielding to the learners as a reasonable degree of control over what Allwright (1981) has called the management of learning. In the specific context of promoting negotiated interaction, management of learning consists chiefly of talk management and topic management." (p. 115)

\section{POTENTIAL CHALLENGES OF THE VSA}

Despite multiple advantages and benefits of the VSA with regard to teaching and learning English, literature still reveals a gap between theoretical assumptions and actual and successful implementation of the sociocultural approaches in EFL settings. Major challenges include factors pertaining to school administration, students, teachers, curriculum, and lack of material resources (Abate, 2014). First of all, the successful implementation of VSA may be hard in schools where administration still sticks to teacher-fronted learning. In fact, if school authority frequently sees students in group discussions with limited teacher talk and fronted instructions, some administrators may tend to think that teachers are poorly performing their duty, which can sometimes end up in negative sanctions for the teacher.

Second, the collaborative learning, as suggested by the sociocultural theory, requires of the teacher to step aside, give learners time and space to work on the activity, and intervene just when assistance is really needed (Samana, 2013). Hence, if students are allowed to take as much time as they need to work on a task, some teachers might have time issues. Indeed, in most EFL settings, teachers are assigned a scripted curriculum with a strict working scheme showing materials to be covered in a school year on a daily basis, which makes teachers feel overwhelmed and powerless to try innovative practices that are helpful to learners (Dresser, 2012).

To make the situation worse, there are school, district, and national exams or tests that are based on the very curriculum. Such high-stake testing plays a great role in students' future as their scores determine what school to go to and what type of financial assistance to get (Ritt, 2016). Consequently, failure to cover the curriculum in a given period may result in poor student performance (Styron \& Strayon, 2012). Again, the teacher is more likely to be the culprit to blame for the learners' failure. To be on a safer side, teachers will tend to teach to the test rather than empowering learners with knowledge and skills they need to become both linguistically and communicatively competent and proficient in the English language. Additionally, instead of focusing on instructional strategies that promote interaction and communication, teachers will spend more time on grammar, vocabulary, and other language aspects covered in exams as Abate (2014) pointed out

"Exam oriented educational system conditions teachers to accommodate themselves in accordance with the prevailing examination systems. It is 
difficult for teachers to use communicative approach in a condition where the examination system is primarily based on grammar, vocabulary, language comprehension and others." (p. 133)

Third, due to low English language proficiency, EFL students may keep quiet and shy, and thus avoid speaking up in class for fear to be rebuked, ridiculed, or punished by teachers or laughed at by classmates when they make mistakes. In the same line, lack of appropriate and effective professional training and qualifications may hinder teachers from feeling comfortable, confident, and self-efficacious enough to implement the VSA in their respective classrooms (Chen \&Goh, 2011).

Finally, in addition to other EFL context-based factors such as larger class size, both teachers and students lack adequate, sufficient, and technology-based teaching and learning materials such as audio, audio-video, books broadcast and podcast, video, etc. (Abate, 2014).

Overall, it is theorized the sociocultural framework has a great potential capacity to promote and sustain an interactive learning environment that is likely to enhance meaning negotiation among learners, which is conducive to language development. "Meaningful negotiation is seen as a result or product of learners' interactional exchanges where communication breakdowns exist (Razak, Saeed, \& Ahmad, 2013, p. 188). However, teachers must be aware of their own teaching context and work on classroom interaction accordingly.

Indeed, it would be deadly erroneous to claim that the VSA offers a magic and exhaustive set of unique solutions to make a class interactive. Indeed, each class is particular, with a particular teacher, teaching a particular topic in a particular context for a particular purpose (Kumaravadivelu, 2003; Kumaravadivelu, 2006).

\section{CONCLUSION}

This paper aimed at shedding light on the potential contribution of the Vygotskian sociocultural framework to mitigating challenges faced in promoting classroom interaction while teaching and learning English as a foreign language. It is theorized that the use of VSA creates and sustains a learning environment where students are likely to actively engage in the learning process, interact with the teacher and among themselves in the meaning construction during the teaching and learning process.

From the discussions throughout the paper, it is hypothesized the Vygotskian sociocultural framework is beneficial at several degrees to enhance interaction in EFL classroom. It offers teachers unique opportunities to inquire and know the learners' background in terms of English language learning experiences, learning styles, needs, concerns, and goals. Such invaluable information helps teachers know the students' current level of English language proficiency of and their potential ability to learn and acquire advanced skills through assistance and peer collaboration. Therefore, the collaborative learning environment offers students space to exchange ideas, share experience and thus learn from one another. Such environment builds partnership and collaboration among learners who no longer struggle individually and isolated from one another. 
The VSA enhance centrality of the learner in the learning/teaching activity. The approach creates more opportunities for learners to express themselves in idea sharing and meaning negotiating, the teachers' attitude of appreciating each students' uniqueness, supporting and encouraging each and every learner to take part in class activities. Consequently, as learners are given enough room to join efforts to reach the same goal, it is more likely that such collaboration may contribute to classroom engagement conducive to better school performance for a given class, and not for some individual students.

\section{REFERENCES}

Abate, E.B. (2014). Prospects and challenges of communicative approach in EFL. Research on Humanities and Social Sciences, 4(25), 128-136.

Andrew, M. D., Cobb, C. D., \& Giampietro, P. J. (2005). Verbal ability and teacher effectiveness. Journal of Teacher Education, 56(4), 343-354.

Asl, E.H. (2015). Comparative study of grammar translation method (GTM) and communicative language teaching (CLT) in language teaching methodology. International Journal of Science and Research Methodology, 1 (3), 16-25.

Behroozizad, S., Namibia, R.M.K., \& Amir, Z. (2014). Sociocultural theory as an approach to aid EFL learners. The Reading Matrix 14(2), 217-226.

Belland, B. R. (2017). Instructional scaffolding in STEM education. Strategies and efficacy evidence. New York, NY: Springer Cham Heidelberg.

Brown, H.D. (2007). Teaching by principles. An interactive approach to language pedagogy. New York: Pearson Education.

Chen, Z., \& Goh, C. C. (2011). Teaching oral English in higher education: Challenges to EFL teachers. Teaching in Higher Education, 16(3), 333-345. http://dx.doi.org/10.1080/09500782.2011.609281

Chin, C. (2007). Teacher questioning in science classrooms: Approaches that stimulate productive thinking. Journal of Research in Science Teaching, 44(6), 815-843.

Dresser, R. (2012). The impact of scripted literacy instruction on teachers and students. Issues in Teacher Education, 21(1), 71-87.

Ellis, R. (2003). Task based language learning and teaching. Oxford: Oxford University Press.

Eun, B. \& Lim, H.S. (2009). A sociocultural view of language learning: The importance of meaning-based instruction. TESL CANADA JOURNAL/REVUE TESL DU CANADA, 27 (1), 13-26.

Farrell, T.S.C. (2007). Reflective language teaching: From research to practice. New York, NY: Continuum.

Felder, R. M., \& Brent, R. (2005). Understanding student differences. Journal of Engineering Education, 94(1), 57-72.

Freire, P. (1970). Pedagogy of the oppressed. New York, NY: The Continuum International Publishing Group.

Friedmann, N. \& Rusou, D. (2015). Critical period for first language: The crucial role of language input during the first year of life. Current Opinion in Neurobiology 35, 27-34. https://doi.org/10.1016/j.conb.2015.06.003 
Gebhard, J.G. (2005). Teaching English as a foreign or second language. A teacher self-development and methodology guide. Michigan: The University of Michigan Press.

Gibbons, P. (2003). Mediating language learning: Teacher interactions with ESL students in a content based classroom. TESOL Quarterly, 37(2), 247-273.

Harland, T. (2003). Vygotsky's Zone of Proximal Development and problem-based learning: linking a theoretical concept with practice through action research. Teaching in Higher Education, 8(2), 263-272.

Haider, M. \&Yasmin, A. (2015). Significance of scaffolding and peer tutoring in the light of Vygotsky's theory of zone of proximal development. International Journal of Languages, Literature and Linguistics, 1( 3), 2015.

Huang, H.M. ( 2002). Toward constructivism for adult learners in online learning environments. British Journal of Educational Technology, 33(1), 27-37.

Ibrahim, M. E. H. (2012).Classroom Interaction in Second Language Teaching and Learning in the Vocational Education Development Centre (VEDC). (Unpublished masters' thesis). British University in Dubai, United Arab Emirates.

Lange, C., Costley, J., \& Han, S.L. (2016). Informal cooperative learning in small groups: The effect of scaffolding on participation. Issues in Educational Research, 26(2), 260-279.

Kessler, C. (Ed.). (1992). Cooperative language learning. New Jersey: Prentice-Hall.

Khaliliaqdam, S. (2014). ZPD, scaffolding and basic speech development in EFL context. Procedia - Social and Behavioral Sciences, 98, 891 - 897. doi:10.1016/j.sbspro.2014.03.497

Kozulin, A. (2003). Psychological tools and mediated learning. In A. Kozulin, B. Gindis, S.A. Vladimir \& M.M. Suzanne (Eds), Vygotsky's educational theory in cultural context. (pp. 1-38). Cambridge: Cambridge University Press.

Kumuravadivelu, B. (2001). Toward a post method pedagogy.TESOL QUATERLY, 35 (4), 537-560.

Kumaravadivelu, B. (2003). Beyond methods. Macro strategies for language teaching. Connecticut: Yale University Press.

Kumaravadivelu, B. (2006). Understanding language teaching. From method to post method. New Jersey: Lawrence Erlbaum Associates.

Lee, J.S. \& Bucholtz, M. (2015). Language socialization across learning spaces (pp. 319-336). In N. Markee (Ed.), The Handbook of classroom discourse and interaction (pp. 319-336). Oxford: Wiley/Blackwell.

Lee, M.S. (2015). Implementing the sociocultural theory while teaching ESL. SPACE: Student Perspectives About Civic Engagement, 1(1), 28-35.

Lin, L. (2016). Investigating Chinese HE EFL Classrooms: Using collaborative learning to enhance learning. Berlin: Springer Berlin Heidelberg.

Lindblom, J. \& Ziemke, T. (2002). Social situatedness: Vygotsky and beyond. Lund University Cognitive Studies 94, 71-78.

Lourenço, O. (2012). Piaget and Vygotsky: Many resemblances, and a crucial difference. New Ideas in Psychology, 30(3), 281-295.

https://doi.org/10.1016/j.newideapsych.2011.12.006 
Mahn, L. (2012). Sociocultural approaches to learning and development: A Vygotskian framework. Educational psychologist, 31(3/4), 191-206.

Mart, C. T. (2013). The grammar-translation method and the use of translation to facilitate learning in ESL classes. Journal of Advances in English Language Teaching, 1(4), 103-105.

Nawrot, E. (2014). "Victor or the wild boy" as a teaching tool for the history of psychology. Teaching of Psychology, 41(3), 237-241. https://doi.org/10.1177/0098628314537977

Nordquist, R. (2017. English as a foreign language (EFL). Thought Co. https://www.thoughtco.com/english-as-a-foreign-language-efl-1690597.

Ohta, A. S. (2001). Second Language Acquisition Processes in the Classroom: Learning Japanese. New Jersey: Lawrence Erlbaum Associates.

Parsell, G. (2000). Asking questions-improving teaching. Medical Education, 34, 592-593. doi:10.1046/j.1365-2923.2000.00750.x

Piaget. J. (1971). Biology and knowledge. An essay on the relations between organic regulation and cognitive process. Chicago, IL: University of Chicago Press.

Poehner, M. E., \& Infante, P. (2016). Mediated development: A Vygotskian approach to transforming second language learner abilities. TESOL Quarterly. Advance online publication. doi: 10.1002/tesq.308

Rahman, F.A., Scaife, J., Yahya, N.A., \&Jalil, H.A. (2010). Knowledge of diverse learners: Implications for the practice of teaching. International Journal of Instruction, 3(2), 83-96.

Razak, N.A., Saeed, M., \& Ahmad, Z. (2013). Adopting social networking sites (SNSs) as interactive communities among English Foreign Language (EFL) learners in writing: opportunities and challenges. English Language Teaching, 6(11), 187-198. doi:10.5539/elt.v6n11p187

Regan ,C. N. (2016). The future of human nature and social progress. A case for Optimism in an age of despair. (Unpublished maters' thesis). BallStateUniversity, United States of America. Retrieved from http://cardinalscholar.bsu.edu/bitstream/handle/123456789/200643/A378_201 6ReganCoreyN-opt.pdf?sequence

Rezaee, A.A., Azizi, Z. (2012). The role of zone of proximal development in the students' learning of English adverbs. Journal of Language Teaching and Research, 3(1), 51-57.

Richards, J.C. \& Rodgers, T. S. (2001). Approaches and methods in language teaching. 2nd ed. New York, NY: Cambridge University Press.

Ritt, M. (2016). The impact of high-stakes testing on the learning environment. (Unpublished masters' thesis). St. Catherine University/University of St. Thomas, United States of America.

Roorda, K. L., Koomen, H. M. Y., Spilt, J. L., \&Oort, F. J. (2011). The influence of teacher-student relationships on student's school engagement and achievement: A meta-analytic approach. Review of Educational Research, 81(4), 493-529.

Rule, P. N. (2015). Dialogue and boundary learning. Boston, MA: Sense Publishers.

Samana, W. (2013). Teacher's and students' scaffolding in an EFL classroom. Academic Journal of Interdisciplinary Studies, 2(8), 338-343. 
Sang, Y. (2017). A conceptual review of age effect on L2 acquisition. Journal of Education and Practice, 8(9), 1-4.

Shaban, K. (2016a). Implications of Vygotsky's sociocultural theory for second language (L2) assessment. Cogent education, 3, (1), 1-10.

Shaban, K. (2016b). Applications of Vygotsky's sociocultural approach for teachers' professional development. Cogent education, 3, 1-10.

Shaban, K., Khatib, M., \& Ebadi, S. (2010). Vygotsky's Zone of Proximal Development: Instructional implications and teachers' professional development. English Language Teaching 3(4), 237-248.

Skidmore, D., Perez-Parent, M., \& Arnfielf, S. (2003).Teacher-pupil dialogue in the guided reading session. Reading: Literacy and Language, 37(2), 47-53.

Styron, J.L \& Strayon, R.A. (2012). Teaching to the test: A controversial issue in quantitative measurement. Systemics, Cybernetics and Informatics, 10(5), 2225.

Sullivan, P., Smith, M., \& Matusov, E. (2009).Bakhtin, Socrates and the carnivalesque in education. New Ideas in Psychology, 27, 326-342. doi:10.1016/j.newideapsych.2008.12.001

Tsang, A. (2017). EFL/ESL teachers' general language proficiency and learners' engagement. RELC Journal, 48(1), 99-113. https://doi.org/10.1177/0033688217690060

Turk, M.C. (2008). The relevance and implications of Vygotsky's sociocultural theory in the second language classroom. ARECLS, 5, 244-262.

Vygotsky, L.S., (1978). Mind in society. The development of higher psychological processes. Cambridge, MA: Harvard University Press.

Vygotsky, L.S. (1998). Collected works. Child psychology. New York, NY: Plenum Press.

Vygotsky, L.S., (1999). Educational psychology. N.W. Boca Raton: CRC Press LLC

Verenikina, I. (2010). Vygotsky in Twenty-First-Century research. In J. Herrington \& B. Hunter (Eds.), Proceedings of World Conference on Educational Multimedia, Hypermedia and Telecommunications (pp. 16-25). Chesapeake, VA: AACE.

Verg, L. \& Kotz, S.A. (2013).How relevant is social interaction in second language learning? Frontiers in Human Neuroscience, 7, 1-7. Doi: $10.3389 /$ fnhum.2013.00550

Wells, G. (1994). The complementary contributions of Holliday and Vygotsky to a language-based theory of learning. Linguistics and Education, 6, 41-90.

Wertsch, J.V. (1985). Vygotsky and the social formation of mind. Cambridge, MA: Harvard University Press.

Wood, D. (1992). 'Teaching Talk: How modes of teacher talk affect pupil participation' in K. Norman, Thinking Voices: The work of the national oracy project (pp. 203-214). London: Holder \& Stoughton.

Wood, J., Bruner J. S. \& Ross, G. (1976). The role of tutoring in problem solving. Journal of Child Psychology and Psychiatry, 17, 89-100. 
Xia, Y. (2014). Language theories and language teaching-from traditional grammar to functionalism. Journal of Language Teaching and Research, 5(3), 559-565.

Xuesong, G.A. (2006). Understanding Chinese students' teacher dependence (China). In T.S.C. Farrel (Ed.), Language teacher research in Asia. Alexandria, Virginia: TESOL.

Zhang, Y. (2008). Classroom discourse and student learning. Asian Social Science 4(9), 80-83. 